\title{
Stage of breast cancer at diagnosis in New Zealand: impacts of socio-demographic factors, breast cancer screening and biology
}

Sanjeewa Seneviratne ${ }^{1,2^{*}}$, Ross Lawrenson ${ }^{1}$, Vernon Harvey ${ }^{3}$, Reena Ramsaroop ${ }^{3}$, Mark Elwood ${ }^{4}$, Nina Scott ${ }^{5}$, Diana Sarfati ${ }^{6}$ and lan Campbell ${ }^{1}$

\begin{abstract}
Background: Examination of factors associated with late stage diagnosis of breast cancer is useful to identify areas which are amenable to intervention. This study analyses trends in cancer stage at diagnosis and impact of socio-demographic, cancer biological and screening characteristics on cancer stage in a population-based series of women with invasive breast cancer in New Zealand.

Methods: All women diagnosed with invasive breast cancer between 2000 and 2013 were identified from two regional breast cancer registries. Factors associated with advanced (stages III and IV) and metastatic (stage IV) cancer at diagnosis were analysed in univariate and multivariate models adjusting for covariates.

Results: Of the 12390 women included in this study 2448 (19.7\%) were advanced and 575 (4.6\%) were metastatic at diagnosis. Māori $(\mathrm{OR}=1.86,1.39-2.49)$ and Pacific $(\mathrm{OR}=2.81,2.03-3.87)$ compared with NZ European ethnicity, other urban $(\mathrm{OR}=2.00,1.37-2.92)$ compared with main urban residency and non-screen $(\mathrm{OR}=6.03,4.41-8.24)$ compared with screen detection were significantly associated with metastatic cancer at diagnosis in multivariate analysis. A steady increase in the rate of metastatic cancer was seen which has increased from 3.8 \% during 2000-2003 to $5.0 \%$ during 2010-2013 period ( $p=0.042)$.

Conclusions: Providing equitable high quality primary care and increasing mammographic screening coverage needs to be looked at as possible avenues to reduce late-stage cancer at diagnosis and to reduce ethnic, socioeconomic and geographical disparities in stage of breast cancer at diagnosis in New Zealand.
\end{abstract}

Keywords: Breast cancer, Stage, Ethnicity, Inequity

\section{Background}

Breast cancer is the commonest cause of cancer in New Zealand women (excluding non-melanoma skin cancer) and accounts for approximately 3000 diagnoses and 600 deaths per year [1]. One of the most important factors in predicting survival from breast cancer is the stage at diagnosis. Women with early stage disease have an excellent prognosis while those with metastatic disease at diagnosis have a 5-year survival of around $20 \%$ [2].

\footnotetext{
*Correspondence: sanjeewa_sa@yahoo.com

${ }^{1}$ Waikato Clinical School, University of Auckland, Hamilton, New Zealand

${ }^{2}$ Department of Surgery, University of Colombo, Colombo, Sri Lanka

Full list of author information is available at the end of the article
}

Stage at diagnosis can be influenced by the diagnostic pathway and the characteristics of the tumour [3]. The diagnostic pathway is important - population based screening with mammography has been shown to increase the proportion of women diagnosed with early breast cancer [4].

In New Zealand, late diagnosis with advanced or metastatic disease has been associated with Mãori ethnicity and social deprivation [5]. Differences by ethnicity and social deprivation have important associations in other countries [6-9], while in some countries it has been shown that women living outside main urban areas are more likely to be diagnosed with advanced disease [10]. 
The reason why women from certain demographic groups may present late may be due to factors related to the women e.g. health literacy, psychosocial factors, etc., [11] or system issues causing diagnostic delays such as a shortage of primary care physicians [12] and difficulty accessing diagnostic facilities [13]. Furthermore, community-level determinants which include health policy, health care delivery system, and community risk factors have also been observed to be contributing to socioeconomic and geographic variations in breast cancer stage at diagnosis [14]. Another cause of advanced stage at diagnosis may be the biology of the cancer - some types of cancer are more aggressive and are more likely to metastasize early [15].

It is important when looking at a population of women with breast cancer to examine the associations with late diagnosis to identify which factors may be amenable to intervention. This study assesses the importance of socio-demographic factors, breast cancer screening and biological factors in explaining differences in cancer stage at diagnosis in a population-based series of female patients diagnosed with invasive breast cancer in New Zealand.

\section{Methods}

\section{Data sources}

Data were obtained from the Auckland (ABCR) and Waikato Breast Cancer Registries (WBCR), which are prospective population based databases that capture almost $100 \%$ of the newly diagnosed breast cancers in the respective regions since 2000 . These two registries cover an area that includes over $40 \%$ of the total New Zealand population. In general, this population resembles average New Zealand population in terms of ethnicity, socioeconomic status and urban/rural residential distribution. Completeness and accuracy of the data included in these registries have been validated previously [16, 17]. Data from the two registries were linked with the New Zealand Cancer Registry (NZCR) and the National Mortality Collection (NMC).

\section{Study population}

All women with primary breast cancer diagnosed over a 13-year period between 01/06/2000 and 31/05/2013 were identified from the two registries. This included a total of 14469 breast cancers [12390 (85.6 \%) invasive and 2079 (14.4\%) in situ cancers]. Of this 12390 women with invasive, primary breast cancer were included in the analyses.

\section{Healthcare system in New Zealand}

New Zealand has a publicly funded national health system that provides specialist and hospital care to all citizens without patient charges. Parallel to the public system, there are a variety of private hospital facilities available, which are mostly funded through insurance schemes. The primary health care system in New Zealand is highly subsidized, but patient co-payment is also substantial. For instance, a visit to a general practitioner on average may cost between NZ\$20 and NZ\$50 for an adult. A national breast cancer screening programme, BreastScreen Aotearoa provides free biannual breast cancer screening for all women aged 45-69 years, and has operated since 1999.

\section{Study covariates}

Patient ethnicity was identified from the breast cancer registries or where it was not available from these registries it was obtained from the NZCR or the NMC, as per the Ministry of Health ethnicity data protocols [18]. Ethnicity was categorized into NZ European, Māori, Pacific, Asian and Other. Socioeconomic deprivation was classified according to the New Zealand Deprivation Index 2006 (NZDep2006) [19]. The NZDep2006 assigns small residential areas a deprivation decile on a scale of 1 to 10 based on nine socio-economic variables measured during the 2006 population census; decile1-least deprived, decile10most deprived. Urban/rural residential status of each woman was categorized into main urban, other urban (independent or satellite urban) and rural based on the New Zealand Statistics urban/rural classification system [20]. These variables were selected on the basis of theoretical relevance and empirical evidence of their utility in assessing the impact of socio-demographic factors on a variety of health outcomes including cancer [21]. Cancer stage at diagnosis was defined according to the Tumour, Node, and Metastasis (TNM) system [22] and was categorized into early (TNM stage groups I and II), advanced (stage groups III and IV) and metastatic (stage group IV) for analysis. Invasive tumour grade was defined according to the Elston and Ellis modified Scarff-Bloom-Richardson breast cancer grading system [23]. Oestrogen (ER) and progesterone (PR) receptor status was determined based on the results of immunohistochemistry tests and classified as positive or negative. HER-2 status was based on Fluorescent In-Situ Hybridization (FISH) test or when this was not available, on immunohistochemistry [24].

\section{Statistical analysis}

Univariate differences in distribution of factors among groups of interest were tested by using Chi squared $(\chi)$ test for trend or by linear-by-linear association test [25]. Unconditional logistic regression models were used to estimate the contribution of covariates towards advanced or metastatic cancer at diagnosis in multivariate analyses. All statistical analyses were performed in SPSS (Version 22) (18). 


\section{Ethics approval}

Both $\mathrm{ABCR}$ and WBCR function with ethics approval from the New Zealand Northern 'A' Health and Disability Ethics Committee. This required individual patient consent from patients for their data to be included. Since 2012, the consent process was waived off by the same ethics committee as it was noted that for data from these registries to be more useful at a national level all patients with breast cancer are needed to be included. Additionally ethical approval for this study was obtained from the same New Zealand Northern 'A' Health and Disability Ethics Committee (Ref. No. 12/NTA/42).

\section{Results}

Of the 12390 women included in this study 9630 (77.7 \%) were from the Auckland Region and 2755 $(22.3 \%)$ from the Waikato. The mean age of the population was 57 years. 8972 (73.3 \%) were NZ European, 1162 (9.5 \%) were Māori, 809 (6.6 \%) were Pacific, 984 (8\%) Asian and 311 (2.5\%) belonged to Other ethnic groups. Ethnicity data were unavailable for 152 (1.2 \%) women. Māori, Pacific and Asian women were significantly younger than the NZ European women, in keeping with the younger age structure of Māori, Pacific and Asian populations in New Zealand [26]. Staging data were missing for $5(0.04 \%)$ while tumour grade was missing for $5.5 \%$ of study women. Information on hormone receptor status was not available for $2.4 \%$ of the study population. HER-2 status was not available for $23.2 \%$ of the women, a majority (84.2\%) of whom were diagnosed with breast cancer prior to 2006.

Distribution of socio-demographic and tumour characteristics by stage at diagnosis are summarized in Table 1 . Proportion of metastatic disease have increased from $3.8 \%$ to $5.0 \%$ over the study period while the rate of stage I cancers has increased from $42.2 \%$ to $45.6 \%$. A corresponding reduction was seen for rates of stage II and III cancers (from $38.0 \%$ to $35.9 \%$ and $15.7 \%$ to $13.6 \%$, respectively). Age younger than 40 and older than 70 years were significantly associated with advanced and metastatic breast cancer at diagnosis compared with women aged between 40 to 69 years, a majority of whom are within the breast cancer screening age. NZ European and Asian women tended to be diagnosed at an earlier stage, compared with Māori and Pacific women. Māori and Pacific women were around two and three times more likely respectively, to be diagnosed with metastatic disease compared with NZ European women $(3.9 \%$ vs. $7.6 \%$ and $10.9 \%$, respectively). Over a third (33.7\%) of the cancers in Pacific women and a quarter of the cancers in Māori (26.1\%) were advanced (stage III or IV) at diagnosis compared with less than a fifth in NZ European (18.3\%) and Asian (17.7 \%) women.
Significantly higher proportions of more advanced cancer, including metastatic cancer were observed in women from high deprivation compared with low deprivation groups and rural compared with urban residing women (Table 1). Proportions of advanced and metastatic cancer were observed to be higher in the Waikato $(21.7 \%$ and $5.9 \%$, respectively) compared with Auckland (19.2\% and $4.3 \%$, respectively). Further, a greater increase in the proportion of metastatic cancer was observed in the Waikato region (58\%) compared with Auckland (17\%) over the study period. Significantly higher proportions of advanced cancer were seen in non-screen compared with screen detected women and in women receiving treatment from public compared with non-public hospitals. Greater proportions of cancers with adverse prognostic characteristics including higher grade, oestrogen (ER) and progesterone receptor (PR) negativity and human epidermal growth factor type-2 (HER-2) positivity were advanced or metastatic at diagnosis compared with lower grade, ER/PR positive and HER-2 negative cancers, respectively.

Multivariate logistic regression models were used to assess the importance of study variables in explaining advanced and metastatic cancer at diagnosis and are shown in Table 2. Patients for whom information on tumour stage $(n=5)$ were not available were excluded from regression analyses. Advanced cancer at diagnosis was significantly associated with Māori [Odds ratio (OR $=1.27,1.08-1.49)]$ and Pacific $(\mathrm{OR}=1.72,1.43-2.06)$ compared with NZ European ethnicity, higher socioeconomic deprivation $(p<0.001)$ and non-screen compared with screen detection $(\mathrm{OR}=3.79,3.33-4.34)$.

Odds ratios for metastatic compared with early stage (i.e., stages I and II) cancer were significantly elevated for Māori $(\mathrm{OR}=1.86,1.39-2.49)$ and Pacific $(\mathrm{OR}=2.81$, 2.03-3.87) women, but not for Asian $(\mathrm{OR}=0.90,0.61$ 1.33 ) or Other $(\mathrm{OR}=1.56,0.86-2.83)$ women, relative to NZ European women (Table 2). Non-screen compared with screen detection ( $\mathrm{OR}=6.03,4.41-8.24)$, other urban compared with main urban residency $(\mathrm{OR}=2.00$, 1.37-2.92), higher socioeconomic deprivation and later year of diagnosis were also significantly associated with metastatic cancer at diagnosis.

Associations between stage at diagnosis and, ethnicity and sociodemographic factors were additionally analysed by year category to identify trends over time (data not shown). However, no significant differences in these associations were observed by year category. As socioeconomic and geographic variables included missing data, regression analysis was repeated using only cases with complete data for all variables. The results were almost identical to the full dataset regression model, and are not presented in this report. Imputation of missing values was not undertaken due to the similarity of these results. 
Table 1 Distribution of selected characteristics by percentage among 12,390 female breast cancer patients diagnosed in New Zealand during 2000-2013

\begin{tabular}{|c|c|c|c|c|c|c|c|c|c|c|c|}
\hline \multirow[t]{3}{*}{ Characteristic } & \multicolumn{2}{|c|}{ Stage I } & \multicolumn{2}{|c|}{ Stage ॥ } & \multicolumn{2}{|c|}{ Stage III } & \multicolumn{2}{|c|}{ Stage IV } & \multirow{3}{*}{$p$} & \multirow{2}{*}{$\begin{array}{l}\text { Total } \\
n\end{array}$} & \multirow[b]{2}{*}{$\%$} \\
\hline & $n$ & $\%$ & $n$ & $\%$ & $n$ & $\%$ & $n$ & $\%$ & & & \\
\hline & 5362 & $43.3 \%$ & 4575 & $36.9 \%$ & 1873 & $15.1 \%$ & 575 & $4.6 \%$ & & 12385 & $100.0 \%$ \\
\hline \multicolumn{12}{|l|}{ Age } \\
\hline$<40$ & 204 & $25.4 \%$ & 333 & $41.5 \%$ & 218 & $27.1 \%$ & 48 & $6.0 \%$ & \multirow[t]{6}{*}{$<0.001$} & 803 & $6.5 \%$ \\
\hline $40-49$ & 1053 & $39.2 \%$ & 1029 & $38.3 \%$ & 492 & $18.3 \%$ & 114 & $4.2 \%$ & & 2688 & $21.7 \%$ \\
\hline $50-59$ & 1603 & $47.8 \%$ & 1144 & $34.1 \%$ & 485 & $14.5 \%$ & 122 & $3.6 \%$ & & 3354 & $27.1 \%$ \\
\hline $60-69$ & 1579 & $55.2 \%$ & 866 & $30.3 \%$ & 311 & $10.9 \%$ & 105 & $3.7 \%$ & & 2861 & $23.1 \%$ \\
\hline $70-79$ & 606 & $38.7 \%$ & 652 & $41.7 \%$ & 202 & $12.9 \%$ & 104 & $6.6 \%$ & & 1564 & $12.6 \%$ \\
\hline $80+$ & 317 & $28.4 \%$ & 551 & $49.4 \%$ & 165 & $14.8 \%$ & 82 & $7.4 \%$ & & 1115 & $9.0 \%$ \\
\hline \multicolumn{12}{|l|}{ Ethnicity } \\
\hline NZ European & 4024 & $44.9 \%$ & 3302 & $36.8 \%$ & 1291 & $14.4 \%$ & 351 & $3.9 \%$ & \multirow[t]{6}{*}{$<0.001$} & 8968 & $73.3 \%$ \\
\hline Māori & 430 & $37.0 \%$ & 428 & $36.8 \%$ & 216 & $18.6 \%$ & 88 & $7.6 \%$ & & 1162 & $9.5 \%$ \\
\hline Pacific & 217 & $26.8 \%$ & 319 & $39.4 \%$ & 186 & $23.0 \%$ & 87 & $10.8 \%$ & & 809 & $6.6 \%$ \\
\hline Asian & 439 & $44.7 \%$ & 370 & $37.6 \%$ & 140 & $14.2 \%$ & 34 & $3.5 \%$ & & 983 & $8.0 \%$ \\
\hline Other & 161 & $51.8 \%$ & 105 & $33.8 \%$ & 31 & $10.0 \%$ & 14 & $4.5 \%$ & & 311 & $2.5 \%$ \\
\hline Unknown & 91 & & 51 & & 9 & & 1 & & & 152 & $(1.2 \%)$ \\
\hline \multicolumn{12}{|c|}{ Menopausal status } \\
\hline Pre & 1291 & $36.1 \%$ & 1402 & $39.2 \%$ & 738 & $20.6 \%$ & 150 & $4.2 \%$ & \multirow[t]{4}{*}{$<0.001$} & 3581 & $29.9 \%$ \\
\hline Peri & 288 & $45.2 \%$ & 239 & $37.5 \%$ & 93 & $14.6 \%$ & 17 & $2.7 \%$ & & 637 & $5.3 \%$ \\
\hline Post & 3554 & $45.8 \%$ & 2821 & $36.4 \%$ & 998 & $12.9 \%$ & 385 & $5.0 \%$ & & 7758 & $64.8 \%$ \\
\hline Unknown & 221 & & 111 & & 44 & & 23 & & & 399 & $(3.2 \%)$ \\
\hline \multicolumn{12}{|l|}{ Year of diagnosis } \\
\hline 2000-2003 & 1262 & $42.4 \%$ & 1131 & $38.0 \%$ & 467 & $15.7 \%$ & 113 & $3.8 \%$ & \multirow[t]{4}{*}{0.001} & 2973 & $24.0 \%$ \\
\hline 2004-2006 & 1097 & $41.1 \%$ & 1016 & $38.0 \%$ & 436 & $16.3 \%$ & 122 & $4.6 \%$ & & 2671 & $21.6 \%$ \\
\hline 2007-2009 & 1309 & $43.3 \%$ & 1094 & $36.2 \%$ & 466 & $15.4 \%$ & 156 & $5.2 \%$ & & 3025 & $24.4 \%$ \\
\hline 2010-2013 & 1694 & $45.6 \%$ & 1334 & $35.9 \%$ & 504 & $13.6 \%$ & 184 & $5.0 \%$ & & 3716 & $30.0 \%$ \\
\hline \multicolumn{12}{|l|}{ Region } \\
\hline Auckland & 4270 & $44.3 \%$ & 3509 & $36.4 \%$ & 1439 & $14.9 \%$ & 412 & $4.3 \%$ & \multirow[t]{2}{*}{$<0.001$} & 9630 & $77.8 \%$ \\
\hline Waikato & 1092 & $39.6 \%$ & 1066 & $38.7 \%$ & 434 & $15.8 \%$ & 163 & $5.9 \%$ & & 2755 & $22.2 \%$ \\
\hline \multicolumn{12}{|l|}{ Deprivation } \\
\hline $1-2$ & 1210 & $46.4 \%$ & 957 & $36.7 \%$ & 353 & $13.5 \%$ & 87 & $3.3 \%$ & \multirow[t]{6}{*}{$<0.001$} & 2607 & $21.2 \%$ \\
\hline $3-4$ & 963 & $47.4 \%$ & 726 & $35.8 \%$ & 268 & $13.2 \%$ & 73 & $3.6 \%$ & & 2030 & $16.5 \%$ \\
\hline $5-6$ & 1166 & $44.4 \%$ & 985 & $37.5 \%$ & 372 & $14.2 \%$ & 105 & $4.0 \%$ & & 2628 & $21.4 \%$ \\
\hline $7-8$ & 1020 & $40.8 \%$ & 913 & $36.5 \%$ & 429 & $17.2 \%$ & 139 & $5.6 \%$ & & 2501 & $20.4 \%$ \\
\hline $9-10$ & 940 & $37.5 \%$ & 958 & $38.3 \%$ & 440 & $17.6 \%$ & 166 & $6.6 \%$ & & 2504 & $20.4 \%$ \\
\hline Unknown & 63 & & 36 & & 11 & & 5 & & & 115 & $(0.9 \%)$ \\
\hline \multicolumn{12}{|l|}{ Urban rural } \\
\hline Main urban & 4064 & $43.7 \%$ & 3421 & $36.8 \%$ & 1417 & $15.2 \%$ & 391 & $4.2 \%$ & $<0.001$ & 9293 & $75.8 \%$ \\
\hline Other urban & 328 & $45.6 \%$ & 262 & $36.4 \%$ & 86 & $12.0 \%$ & 43 & $6.0 \%$ & & 719 & $5.9 \%$ \\
\hline Rural & 901 & $40.0 \%$ & 855 & $38.0 \%$ & 358 & $15.9 \%$ & 136 & $6.0 \%$ & & 2250 & $18.3 \%$ \\
\hline Unknown & 69 & & 37 & & 12 & & 5 & & & 123 & $(1.0 \%)$ \\
\hline Mode of detectio & & & & & & & & & & & \\
\hline Screen & 3196 & $67.2 \%$ & 1211 & $25.5 \%$ & 296 & $6.2 \%$ & 51 & $1.1 \%$ & $<0.001$ & 4754 & $38.4 \%$ \\
\hline
\end{tabular}


Table 1 Distribution of selected characteristics by percentage among 12,390 female breast cancer patients diagnosed in New Zealand during 2000-2013 (Continued)

\begin{tabular}{|c|c|c|c|c|c|c|c|c|c|c|c|}
\hline Non-screen & 2166 & $28.4 \%$ & 3364 & $44.1 \%$ & 1577 & $20.7 \%$ & 524 & $6.9 \%$ & & 7631 & $61.6 \%$ \\
\hline \multicolumn{12}{|l|}{ Grade } \\
\hline । & 2003 & $70.1 \%$ & 694 & $24.3 \%$ & 134 & $4.7 \%$ & 26 & $0.9 \%$ & \multirow[t]{4}{*}{$<0.001$} & 2857 & $24.4 \%$ \\
\hline$\|$ & 2324 & $42.7 \%$ & 2137 & $39.2 \%$ & 821 & $15.1 \%$ & 167 & $3.1 \%$ & & 5449 & $46.5 \%$ \\
\hline III & 858 & $25.2 \%$ & 1548 & $45.4 \%$ & 820 & $24.1 \%$ & 180 & $5.3 \%$ & & 3406 & $29.1 \%$ \\
\hline Unknown & 177 & & 196 & & 98 & & 202 & & & 673 & (5.4\%) \\
\hline \multicolumn{12}{|l|}{ ER/PR } \\
\hline ER/PR Positive & 4526 & $46.1 \%$ & 3545 & $36.1 \%$ & 1381 & $14.1 \%$ & 373 & $3.8 \%$ & \multirow[t]{3}{*}{$<0.001$} & 9825 & $81.3 \%$ \\
\hline ER \& PR Negative & 716 & $31.7 \%$ & 928 & $41.0 \%$ & 471 & $20.8 \%$ & 146 & $6.5 \%$ & & 2261 & $18.7 \%$ \\
\hline Unknown & 120 & & 102 & & 21 & & 56 & & & 299 & (2.4 \%) \\
\hline \multicolumn{12}{|l|}{ HER-2 } \\
\hline Positive & 465 & $29.2 \%$ & 576 & $36.2 \%$ & 418 & $26.3 \%$ & 132 & $8.3 \%$ & \multirow[t]{4}{*}{$<0.001$} & 1591 & $16.7 \%$ \\
\hline Equivocal & 99 & $48.5 \%$ & 73 & $35.8 \%$ & 27 & $13.2 \%$ & 5 & $2.5 \%$ & & 204 & $2.1 \%$ \\
\hline Negative & 3449 & $44.7 \%$ & 2861 & $37.0 \%$ & 1110 & $14.4 \%$ & 302 & $3.9 \%$ & & 7722 & $81.1 \%$ \\
\hline Unknown & 1349 & & 1065 & & 318 & & 136 & & & 2868 & $(23.2 \%)$ \\
\hline \multicolumn{12}{|l|}{ Histology } \\
\hline Ductal & 4378 & $44.2 \%$ & 3644 & $36.8 \%$ & 1476 & $14.9 \%$ & 409 & $4.1 \%$ & \multirow[t]{5}{*}{$<0.001$} & 9907 & $81.3 \%$ \\
\hline Lobular & 480 & $34.3 \%$ & 570 & $40.7 \%$ & 281 & $20.1 \%$ & 68 & $4.9 \%$ & & 1399 & $11.5 \%$ \\
\hline Mixed & 19 & $26.8 \%$ & 30 & $42.3 \%$ & 21 & $29.6 \%$ & 1 & $1.4 \%$ & & 71 & $0.6 \%$ \\
\hline Other & 450 & $55.9 \%$ & 255 & $31.7 \%$ & 62 & $7.7 \%$ & 38 & $4.7 \%$ & & 805 & $6.6 \%$ \\
\hline Unknown & 35 & & 76 & & 33 & & 59 & & & 203 & $(1.6 \%)$ \\
\hline
\end{tabular}

\section{Discussion}

This study has shown major and significant differences in stage of breast cancer at diagnosis by ethnicity, socioeconomic status and by urban/rural residency in New Zealand. We also observed a significant rise in the proportion of metastatic breast cancer although the overall proportion of advanced breast cancer did not show a significant change over the 13 year study period.

Differences in rate of advanced or metastatic breast cancer by ethnicity and socioeconomic status may be due, in part, to delays in responding to breast symptoms which may differ between ethnic and socioeconomic groups. Such differences occur because of differences in access to care or due to patient factors which include health literacy, health seeking behaviours or psychosocial factors [27-29]. Structural organization of the healthcare system also contributes to these disparities by forming barriers to access primary health care services for women of minority ethnicity, low socioeconomic status or non-urban residency [30]. For example, a short supply of primary care physicians has been associated with late stage of breast cancer at diagnosis [12]. Difficulties in accessing primary care due lack of general practitioners (GP) especially outside main urban areas, the costs associated with accessing GPs and barriers due to services not being culturally safe are well-established in New Zealand [31, 32]. A relative lack of GPs commonly seen in rural and low socioeconomic areas may lead to patient overload and hence, a lower quality of care. For instance, if doctors only have a short time to see patients then they may be less likely to undertake routine examinations or ask about the presence of breast lumps. All these factors contribute to a delay and more advanced cancer stage at diagnosis which leads to poor cancer outcomes [33].

Improved delivery of primary health care and increasing mammographic breast cancer screening coverage, as observed in New Zealand over the last two decades [31], would be expected to have reduced the rate of advanced and metastatic cancer at diagnosis. In contrast, the present study observed a steady increase in the proportion of metastatic breast cancer at diagnosis. A similar scenario is reported from several other developed countries including the USA, where the rate of metastatic cancer has remained static or has steadily increased over the last two to three decades [34]. This rise has been more pronounced among women younger than 50 years [35]. It is unclear whether the observed increase in metastatic cancer in our study population is an actual increase or an apparent increase due to several other reasons. For instance, stage migration due to improvements in diagnostic imaging technology, or increasing use of imaging studies 
Table 2 Multivariate analysis for factors associated with advanced and metastatic breast cancer versus early breast cancer at diagnosis, 2000-2013

\begin{tabular}{|c|c|c|c|c|c|c|c|c|c|c|c|c|}
\hline \multirow[t]{2}{*}{ Characteristic } & \multicolumn{6}{|c|}{ Univariate } & \multicolumn{6}{|c|}{ Adjusted } \\
\hline & $\mathrm{OR}$ & Advanced 95\% Cl & $p$ & OR & Metastatic $95 \% \mathrm{Cl}$ & $p$ & $\mathrm{OR}$ & Advanced $95 \% \mathrm{Cl}$ & $p$ & OR & Metastatic $95 \% \mathrm{Cl}$ & $p$ \\
\hline \multicolumn{13}{|l|}{ Age } \\
\hline$<40$ & 1.70 & $1.43-2.02$ & & 1.63 & $1.15-2.31$ & & 1.10 & $0.92-1.32$ & & 1.03 & $0.70-1.50$ & \\
\hline $40-49$ & Ref & & 0.000 & Ref & & 0.000 & Ref & & 0.000 & Ref & & 0.021 \\
\hline $50-59$ & 0.76 & $0.67-0.86$ & & 0.81 & $0.62-1.05$ & & 1.10 & $0.96-1.26$ & & 1.24 & $0.93-1.65$ & \\
\hline $60-69$ & 0.59 & $0.51-0.67$ & & 0.78 & $0.60-1.03$ & & 0.90 & $0.78-1.05$ & & 1.19 & $0.88-1.61$ & \\
\hline $70-79$ & 0.84 & $0.72-0.98$ & & 1.51 & $1.15-1.99$ & & 0.85 & $0.72-1.00$ & & 1.50 & $1.10-2.04$ & \\
\hline $80+$ & 0.98 & $0.83-1.16$ & & 1.72 & $1.29-2.32$ & & 0.76 & $0.63-0.91$ & & 0.84 & $0.59-1.21$ & \\
\hline \multicolumn{13}{|l|}{ Year of diagnosis } \\
\hline 2000-2003 & Ref & & 0.068 & Ref & & 0.079 & Ref & & 0.311 & Ref & & 0.042 \\
\hline 2004-2006 & 1.09 & $0.96-1.24$ & & 1.22 & $0.94-1.59$ & & 0.93 & $0.80-1.08$ & & 1.19 & $0.87-1.64$ & \\
\hline 2007-2009 & 1.07 & $0.94-1.21$ & & 1.37 & $1.07-1.76$ & & 0.95 & $0.81-1.12$ & & 1.51 & $1.10-2.07$ & \\
\hline 2010-2013 & 0.94 & $0.83-1.06$ & & 1.29 & $1.01-1.65$ & & 0.87 & $0.75-1.02$ & & 1.44 & $1.06-1.96$ & \\
\hline \multicolumn{13}{|l|}{ Region } \\
\hline Auckland & Ref & & 0.004 & Ref & & 0.000 & Ref & & 0.741 & Ref & & 0.903 \\
\hline Waikato & 1.16 & $1.05-1.29$ & & 1.43 & $1.18-1.72$ & & 1.03 & $0.85-1.24$ & & 0.98 & $0.68-1.42$ & \\
\hline \multicolumn{13}{|l|}{ Ethnicity } \\
\hline NZ European & Ref & & & Ref & & & Ref & & & Ref & & \\
\hline Maori & 1.58 & $1.37-1.82$ & 0.000 & 2.14 & $1.68-2.73$ & 0.000 & 1.27 & $1.08-1.49$ & 0.004 & 1.86 & $1.39-2.49$ & 0.000 \\
\hline Pacific & 2.27 & $1.95-2.65$ & 0.000 & 3.38 & $2.64-4.35$ & 0.000 & 1.72 & $1.43-2.06$ & 0.000 & 2.81 & $2.03-3.87$ & 0.000 \\
\hline Asian & 0.96 & $0.81-1.14$ & 0.639 & 0.88 & $0.61-1.26$ & 0.475 & 0.81 & $0.67-0.98$ & 0.026 & 0.90 & $0.61-1.33$ & 0.609 \\
\hline Other & 0.76 & $0.55-1.04$ & 0.755 & 1.10 & $0.64-1.90$ & 0.737 & 0.87 & $0.62-1.23$ & 0.426 & 1.56 & $0.86-2.83$ & 0.146 \\
\hline Unknown & 0.31 & $0.17-0.60$ & 0.000 & 0.15 & $0.02-1.05$ & 0.056 & 0.37 & $0.19-0.72$ & 0.003 & 0.22 & $0.03-1.63$ & 0.139 \\
\hline \multicolumn{13}{|l|}{ Deprivation } \\
\hline $1-2$ & Ref & & 0.000 & Ref & & 0.000 & Ref & & 0.000 & Ref & & 0.017 \\
\hline $3-4$ & 0.99 & $0.85-1.16$ & & 1.08 & $0.78-1.48$ & & 0.96 & $0.81-1.14$ & & 0.84 & $0.59-1.19$ & \\
\hline $5-6$ & 1.09 & $0.95-1.26$ & & 1.21 & $0.91-1.63$ & & 1.05 & $0.90-1.23$ & & 0.99 & $0.71-1.36$ & \\
\hline $7-8$ & 1.45 & $1.26-1.66$ & & 1.79 & $1.36-2.36$ & & 1.31 & $1.12-1.53$ & & 1.40 & $1.02-1.92$ & \\
\hline $9-10$ & 1.57 & $1.37-1.80$ & & 2.18 & $1.67-2.84$ & & 1.28 & $1.09-1.51$ & & 1.40 & $1.01-1.92$ & \\
\hline Unknown & 0.80 & $0.46-1.36$ & & 1.26 & $0.50-3.18$ & & 0.79 & $0.14-4.47$ & & 0.94 & $0.01-109$ & \\
\hline
\end{tabular}


Table 2 Multivariate analysis for factors associated with advanced and metastatic breast cancer versus early breast cancer at diagnosis, 2000-2013 (Continued)

\begin{tabular}{|c|c|c|c|c|c|c|c|c|c|c|c|c|}
\hline \multicolumn{13}{|l|}{ Urban rural } \\
\hline Main urban & Ref & & 0.009 & Ref & & 0.001 & Ref & & 0.981 & Ref & & 0.004 \\
\hline Other urban & 0.91 & $0.74-1.10$ & & 1.40 & $1.01-1.93$ & & 1.03 & $0.83-1.29$ & & 2.00 & $1.37-2.92$ & \\
\hline Rural & 1.16 & $1.04-1.30$ & & 1.48 & $1.21-1.81$ & & 1.01 & $0.82-1.25$ & & 1.22 & $0.83-1.82$ & \\
\hline Unknown & 0.66 & $0.40-1.11$ & & 0.90 & $0.37-2.28$ & & 0.78 & $0.15-4.18$ & & 0.40 & $0.01-46.1$ & \\
\hline \multicolumn{13}{|l|}{ Mode of detection } \\
\hline Screen & Ref & & 0.000 & Ref & & 0.000 & Ref & & 0.000 & Ref & & 0.000 \\
\hline Non-screen & 4.83 & $4.28-5.44$ & & 8.18 & $6.13-10.9$ & & 3.79 & $3.33-4.34$ & & 6.03 & $4.41-8.24$ & \\
\hline \multicolumn{13}{|l|}{ ER/PR status } \\
\hline ER/PR Positive & Ref & & 0.000 & Ref & & 0.000 & Ref & & 0.070 & Ref & & 0.620 \\
\hline ER \& PR Negative & 1.73 & $1.55-1.92$ & & 1.92 & $1.58-2.34$ & & 1.13 & $0.99-1.28$ & & 1.06 & $0.83-1.36$ & \\
\hline Unknown & 1.60 & $1.23-2.08$ & & 5.45 & $4.00-7.45$ & & 1.50 & $1.06-2.14$ & & 1.12 & $0.71-1.79$ & \\
\hline \multicolumn{13}{|l|}{ Grade } \\
\hline Grade I & Ref & & 0.000 & Ref & & 0.000 & Ref & & 0.000 & Ref & & 0.000 \\
\hline Grade II & 3.73 & $3.13-4.44$ & & 3.88 & $2.56-5.88$ & & 2.85 & $2.38-3.40$ & & 2.72 & $1.78-4.14$ & \\
\hline Grade III & 7.00 & $5.88-8.35$ & & 7.76 & $5.12-11.7$ & & 4.13 & $3.30-5.00$ & & 3.85 & $2.47-5.99$ & \\
\hline Unknown & 13.6 & $10.8-16.9$ & & 56.2 & $36.8-85.7$ & & 12.7 & $9.82-16.4$ & & 49.6 & $31.2-79.1$ & \\
\hline \multicolumn{13}{|l|}{ HER-2 status } \\
\hline Negative & Ref & & 0.000 & Ref & & 0.000 & Ref & & 0.000 & Ref & & 0.000 \\
\hline Equivocal & 0.83 & $0.57-1.22$ & & 0.61 & $0.25-1.49$ & & 0.73 & $0.48-1.10$ & & 0.46 & $0.18-1.19$ & \\
\hline Positive & 2.36 & $2.10-2.66$ & & 2.65 & $2.13-3.28$ & & 1.57 & $1.38-1.79$ & & 1.80 & $1.41-2.31$ & \\
\hline Unknown & 0.84 & $0.75-0.94$ & & 1.18 & $0.96-1.45$ & & 0.63 & $0.54-0.74$ & & 0.63 & $0.45-0.87$ & \\
\hline
\end{tabular}


for staging over time might have placed patients in a higher stage group at diagnosis [36]. Stage migration tends to occur from an adjacent category (e.g., from stage I or stage III to stage II) and usually from a lower to the next higher stage category (e.g., stage III to stage IV). In keeping with this, our study also observed a reduction in the proportion of stage III cancer which was approximately equal to the increase in rate of metastatic cancer. Regardless, the trajectory of the proportion of metastatic breast cancer predicts a likely increase in the number of women being diagnosed with metastatic breast cancer in the future.

Some researchers argue that the lack of a decrease in rate of metastatic breast cancer observed in many developed countries is a reflection of the ineffectiveness of programmes aimed at improving early diagnosis of breast cancer which include mammographic breast cancer screening [34]. However, it is possible that a majority of these women who are diagnosed with metastatic breast cancer are the very same women who have poor access to health care services, and hence fail to be captured by mammographic screening programmes. As seen in the present study, only a very small proportion of cancers among women who are diagnosed through mammographic screening are metastatic at diagnosis and the vast majority of metastatic cancers are diagnosed in women with symptomatic cancer. Furthermore, many researchers have estimated that approximately a half of the reduction in breast cancer mortality observed in the last two decades in the developed world has been due to widespread use of mammographic screening $[37,38]$. Therefore it is unlikely that mammographic screening is ineffective, rather it is the lack of penetration of these programmes into populations of deprived women who are likely to gain a greater benefit that limits its effectiveness at population level.

Increasing rate of metastatic cancer poses several challenges. First, the healthcare system needs to be geared up to deal with women with metastatic cancer whose numbers are likely to increase. Many of these women nowadays have prolonged survivals due to improved treatments [39] which will further increase the disease burden on the health system. In addition to controlling metastatic disease with various treatments, these women will also require expanded services to provide long-term palliative care and psychosocial support. Second, it is essential to identify the reasons for the failure of present health strategies to reduce the rates of advanced and metastatic breast cancer in New Zealand. Identification of sub-groups of women who are at risk of being diagnosed with metastatic cancer, as shown in this study may help develop strategies specifically targeting these groups to promote early diagnosis.

Potential limitations of this study include use of area level deprivation as a proxy measure for individual socioeconomic status and missing data for some of the included variables. The NZDep2006 has been validated as an accurate proxy measure for assessment of socioeconomic deprivation for epidemiological studies [40], although it inherently has a limited precision to predict individual deprivation. Further, we did not include data on health insurance status or lifestyle factors (e.g., weight or body mass index, physical activity, diet, etc.,) or BRCA or other genetic panel-type testing that can influence breast cancer risk and possibly likelihood of screening in our analyses as these were not available from the registries. The analysis performed including only complete dataset yielded very similar results to the results shown; hence missing data are unlikely to have affected the reported findings significantly. Strengths of this study include the completeness of the sample, which essentially included $100 \%$ of newly diagnosed cancers over the study period, and the comprehensive nature of the prospectively collected data from the registries. Hence, these study findings are likely to be representative of breast cancer in New Zealand.

In conclusion, this study has shown significant differences in the proportions of advanced and metastatic breast cancer at diagnosis by ethnicity, socioeconomic status and geography. Further, a small but a significant increase in the proportion of metastatic breast cancer was observed over time. While ensuring increasing provisions to manage metastatic breast cancer, steps needed to be instituted to promote early diagnosis to reduce the rate of metastatic breast cancer at diagnosis. Increasing breast cancer screening coverage and increasing health literacy especially among deprived populations who are at a greater risk of being diagnosed with advanced breast cancer may help reduce the rate of metastatic breast cancer at diagnosis and reduce disparities in stage at diagnosis.

Competing interests

All authors declare that there are no conflicts of interest.

\section{Author contributions}

SS, ME and RL developed the concept, designed the study, developed the methodology, collected data and performed the analysis. SS wrote up the initial version of the manuscript and IC, NS, RL, RR, VH, DS and ME provided comments. All authors contributed to the final version of the manuscript. All authors read and approved the final manuscript.

\section{Acknowledgements}

We acknowledge funding support received from the Health Research Council of New Zealand (Grant No. 14/484) for this study.

\section{Author details}

${ }^{1}$ Waikato Clinical School, University of Auckland, Hamilton, New Zealand.

${ }^{2}$ Department of Surgery, University of Colombo, Colombo, Sri Lanka.

${ }^{3}$ Auckland District Health Board, Auckland, New Zealand. ${ }^{4}$ School of

Population Health, University of Auckland, Auckland, New Zealand. ${ }^{5}$ Māori

Health Services, Waikato District Health Board, Hamilton, New Zealand.

${ }^{6}$ University of Otago, Wellington, New Zealand. 
Received: 4 September 2015 Accepted: 15 February 2016

\section{-}

\section{References}

1. Ministry of Health: Cancer: New Registrations and Deaths 2012. In. Wellington: Ministry of Health; 2015.

2. Cardoso F, Harbeck N, Fallowfield L, Kyriakides S, Senkus E. Locally recurrent or metastatic breast cancer: ESMO Clinical Practice Guidelines for diagnosis, treatment and follow-up. Ann Oncol. 2012;23 suppl 7:vii11-9.

3. Hunter CP, Redmond CK, Chen WW, Austin DF, Greenberg RS, Correa P, et al. Breast cancer: factors associated with stage at diagnosis in black and white women. J Natl Cancer Inst. 1993;85(14):1129-37.

4. Otto SJ, Fracheboud J, Verbeek AL, Boer R, Reijerink-Verheij JC, Otten JD, et al. Mammography screening and risk of breast cancer death: a populationbased case-control study. Cancer Epidemiol Biomark Prev. 2012;21(1):66-73.

5. Seneviratne S, Campbell I, Scott N, Shirley R, Lawrenson R. Impact of mammographic screening on ethnic and socioeconomic inequities in breast cancer stage at diagnosis and survival in New Zealand: a cohort study. BMC Public Health. 2015;15(1):46.

6. Li Cl, Malone KE, Daling JR. Differences in breast cancer stage, treatment, and survival by race and ethnicity. Arch Intern Med. 2003;163(1):49-56.

7. Farley TA, Flannery JT. Late-stage diagnosis of breast cancer in women of lower socioeconomic status: public health implications. Am J Public Health. 1989;79(11):1508-12

8. Wang Q, Li J, Zheng S, Li J-Y, Pang Y, Huang R, et al. Breast cancer stage at diagnosis and area-based socioeconomic status: a multicenter 10-year retrospective clinical epidemiological study in China. BMC Cancer. 2012; 12(1):122.

9. Flores YN, Davidson PL, Nakazono TT, Carreon DC, Mojica CM, Bastani R. Neighborhood socio-economic disadvantage and race/ethnicity as predictors of breast cancer stage at diagnosis. BMC Public Health. 2013; 13(1):1061.

10. Barry J, Breen N. The importance of place of residence in predicting latestage diagnosis of breast or cervical cancer. Health Place. 2005;11(1):15-29.

11. Macleod U, Mitchell E, Burgess C, Macdonald S, Ramirez A. Risk factors for delayed presentation and referral of symptomatic cancer: evidence for common cancers. Br J Cancer. 2009;101:S92-S101.

12. Ferrante JM, Gonzalez EC, Pal N, Roetzheim RG. Effects of physician supply on early detection of breast cancer. J Am Board Fam Pract. 2000;13(6):408-14.

13. Amey $\mathrm{CH}$, Miller MK, Albrecht SL. The role of race and residence in determining stage at diagnosis of breast cancer. J Rural Health. 1997;13(2): 99-108.

14. Davidson PL, Bastani R, Nakazono TT, Carreon DC. Role of community risk factors and resources on breast carcinoma stage at diagnosis. Cancer. 2005; 103(5):922-30

15. Hunter CP. Epidemiology, stage at diagnosis, and tumor biology of breast carcinoma in multiracial and multiethnic populations. Cancer. 2000; 88(S5):1193-202.

16. Seneviratne S, Campbell I, Scott N, Shirley R, Peni T, Lawrenson R. Accuracy and completeness of the New Zealand Cancer Registry for staging of invasive breast cancer. Cancer Epidemiol. 2014;38(5):638-44.

17. Neave L, Harvey V, Benjamin C, Thompson P, Pellett O, Whitlock J, et al. The Auckland breast cancer register: a special project of the Auckland breast cancer study group. N Z Med J. 2003;116(1184):U648.

18. Ethnicity Data Protocols for the Health and Disability Sector [http://www. health.govt.nz/publication/ethnicity-data-protocols-health-and-disability-sector]. Accessed on 13/03/2015.

19. Salmond C, Crampton P, Atkinson J. NZDep2006: Index of Deprivation. Wellington: Department of Public Health, University of Otago; 2007.

20. Statistics New Zealand. New Zealand: An Urban/Rural Profile Update. Wellington: Statistics New Zealand; 2006.

21. Mandelblatt JS, Yabroff KR, Kerner JF. Equitable access to cancer services: A review of barriers to quality care. Cancer. 1999;86(11):2378-90

22. American Joint Committee on Cancer. AJCC Cancer Staging Manual. 7th ed. New York: Springer; 2010.

23. Elston CW, Ellis IO. Pathological prognostic factors in breast cancer: the value of histological grade in breast cancer: experience from a large study with long-term follow-up. Histopathology. 1991;19(5):403-10.

24. Pauletti G, Godolphin W, Press MF, Slamon DJ. Detection and quantitation of HER-2/neu gene amplification in human breast cancer archival material using fluorescence in situ hybridization. Oncogene. 1996;13(1):63-72.
25. Agresti A. Categorical data analysis. 2nd ed. New York: Wiley-Interscience; 2002.

26. Robson B, Harris R. Hauora: Màori Standards of Health IV. A study of the years 2000-2005. Wellington: Te Ròpù Rangahau Hauora a Eru Pòmare; 2007.

27. Koay K, Schofield P, Jefford M. Importance of health literacy in oncology. Asia Pac J Clin Oncol. 2012;8(1):14-23.

28. Bish A, Ramirez A, Burgess C, Hunter M. Understanding why women delay in seeking help for breast cancer symptoms. J Psychosom Res. 2005;58(4):321-6.

29. Lannin DR, Mathews HF, Mitchell J, Swanson MS, Swanson FH, Edwards MS. Influence of socioeconomic and cultural factors on racial differences in latestage presentation of breast cancer. Jama. 1998;279(22):1801-7.

30. Shavers VL, Brown ML. Racial and ethnic disparities in the receipt of cancer treatment. J Natl Cancer Inst. 2002;94(5):334-57.

31. Brabyn L, Barnett AR: Population need and geographical access to general practitioners in rural New Zealand. 2004

32. Malcolm L. Inequities in access to and utilisation of primary medical care services for Maori and low income New Zealanders. N Z Med J. 1996; 109(1030):356-8.

33. Richards MA, Westcombe AM, Love SB, Littlejohns P, Ramirez AJ. Influence of delay on survival in patients with breast cancer: a systematic review. Lancet. 1999;353(9159):1119-26.

34. Bleyer $\mathrm{A}$, Welch $\mathrm{HG}$. Effect of three decades of screening mammography on breast-cancer incidence. N Engl J Med. 2012:367(21):1998-2005.

35. Johnson RH, Chien FL, Bleyer A. Incidence of breast cancer with distant involvement among women in the United States, 1976 to 2009. JAMA. 2013;309(8):800-5

36. Polednak AP. Increase in distant stage breast cancer incidence rates in US women aged 25-49 years, 2000-2011: the stage migration hypothesis. J Cancer Epidemiol. 2015;2015:710106.

37. Berry DA, Cronin KA, Plevritis SK, Fryback DG, Clarke L, Zelen M, et al. Effect of screening and adjuvant therapy on mortality from breast cancer. N Engl J Med. 2005:353(17):1784-92.

38. Kalager M, Zelen M, Langmark F, Adami H-O. Effect of screening mammography on breast-cancer mortality in Norway. N Engl J Med. 2010: 363(13):1203-10

39. Chia SK, Speers CH, D'yachkova Y, Kang A, Malfair-Taylor S, Barnett J, et al. The impact of new chemotherapeutic and hormone agents on survival in a population-based cohort of women with metastatic breast cancer. Cancer. 2007;110(5):973-9

40. Salmond CE, Crampton P. Development of New Zealand's deprivation index (NZDep) and its uptake as a national policy tool. Can J Public Health. 2012; 103(8 Suppl 2):S7-11.

\section{Submit your next manuscript to BioMed Central and we will help you at every step:}

- We accept pre-submission inquiries

- Our selector tool helps you to find the most relevant journal

- We provide round the clock customer support

- Convenient online submission

- Thorough peer review

- Inclusion in PubMed and all major indexing services

- Maximum visibility for your research

Submit your manuscript at www.biomedcentral.com/submit
) Biomed Central 